\title{
Analisis Tingkat Preferensi Pemilihan Moda Transportasi Antar Kota Antar Provinsi dengan Metode AHP Topsis (Study Kasus Rute Cilacap - Yogyakarta)
}

\section{Analysis of Preference Level of Intercity Transportation Mode Selection Between Province With AHP Topsis Method (Case Study of the Cilacap Route - Yogyakarta)}

\author{
Gandha Yugo Prasetyo ${ }^{1 *}$, Imam Muthohar ${ }^{2}$, Siti Malkhamah $^{3}$ \\ 1,2,3Prodi Magister Teknik Sipil Departemen Teknik Sipil dan Lingkungan, Universitas Gajah Mada
}

\section{ARTICLE INFO}

Article history:

DOI:

$\underline{10.30595 / p s p f s . v 1 i .155}$

Submitted:

June 28, 2021

Accepted:

July 10, 2021

Published:

Oct 31, 2021

Keywords:

AHP - TOPSIS, Preference of

Transportation Mode,

Sensitivity

\begin{abstract}
There are different characteristics between the modes of land transportation, such as trains, buses and cars from Cilacap to Yogyakarta, the Inter-City Inter-Provincial route. This gave a question of what criteria a person chose in determining the mode of transportation preferences. A questionnaire was required for data collection, determining the number of respondents (users). There were 20 respondents; $55 \%$ have low income, $10 \%$ have middle income, $35 \%$ have a high income. Then the data from filling out the questionnaire was analyzed using the AHP-TOPSIS method to determine the weight of the research criteria that had the most influence on preferences for transportation modes. With the results of the weighted criteria: safety (47.80\%), comfort $(19.78 \%)$, travel time $(12.47 \%)$, frequency $(12.12 \%)$ and cost (7.83\%). Furthermore, the results of the preferences for the choice of transportation modes showed that the first rank was achieved by cars $(0.73)$, secondly by buses $(0.66)$ and thirdly by trains $(0.58)$. The sensitivity test results showed that increasing the weight of the comfort criteria would reduce the priority of the bus mode. As for the training mode, it could be increased by adding weight to the cost criteria.
\end{abstract}

This work is licensed under a Creative Commons Attribution 4.0 International License.

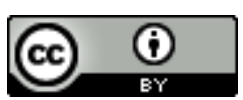

\section{Corresponding Author:}

Gandha Yugo Prasetyo

Prodi Magister Teknik Sipil Departemen Teknik Sipil dan Lingkungan, Universitas Gajah Mada

Jl Grafika No. 2 Kampus UGM Yogyakarta 53182 Telp. (0274) 631178

Email: gandhayugo92@mail.ugm.ac.id

\section{PENDAHULUAN}

Mempertimbangkan pemilihan moda transportasi mana yang paling utama bagi orang sangatlah penting. Ada beberapa kriteria utama dalam pemilihan moda yaitu waktu, tarif, frekuensi, aksesibilitas, kenyamanan, keselamatan dan keselamatan. Preferensi utama moda transportasi dapat diketahui dari bobot masing-masing kriteria. Pemilihan moda transportasi dari Kabupaten Cilacap menuju Yogyakarta dapat dilihat dari berbagai alternatif antara lain kereta api, mobil dan bus. Moda transportasi tersebut memiliki keunggulan dan kekurangan pada tiap-tiap kriteria. Hal inilah yang dapat mempengaruhi preferensi orang dalam memilih moda transportasi dari Cilacap menuju Yogyakarta. Penelitian ini bertujuan untuk:

a. Mengidentifikasi nilai kriteria yang dapat mempengaruhi preferensi dalam memilih moda transportasi dari Cilacap menuju Yogyakarta.

b. Menganalisis pengaruh tiap-tiap nilai kriteria sebagai penentu pemilihan alternatif moda transportasi dari Cilacap menuju Yogyakarta. 
c. Menganalisis pengaruh perubahan nilai kriteria terhadap preferensi dalam pemilihan alternatif moda transportasi dari Cilacap menuju Yogyakarta.

d. Menyusun saran-saran untuk meningkatkan penggunaan alternatif moda transportasi dari Cilacap menuju Yogyakarta.

Manfaat yang diharapkan dalam penelitian ini adalah sebagai gambaran dan masukan kepada pemerintah dalam mengembangkan transportasi antar kota antar provinsi. Kemudian Penelitian ini dapat digunakan bagi operator transportasi dalam meningkatkan pelayanan transportasi antar kota antar provinsi, serta dapat dijadikan referensi dan informasi kepada masyarakat.

Penelitian ini menggunakan salah satu sistem pendukung keputusan yaitu Multi Attribute Decision Making (MADM). Menurut Beinant, 2001 di dalam penelitian Anjali Awasthi, Hichem Omrani, Philippe Gerber, 2018 mengatakan bahwa MADM merupakan kerangka kerja untuk penataan masalah keputusan serta merupakan satu set metode untuk menghasilkan preferensi di antara alternatif. Keuntungan mengunakan metode tersebut adalah kemamapuan untuk memperhitungkan konflik multidimensi yang tidak dapat dibandingkan dan ketidakpastian efek dari keputusan secara eksplisit. MADM memiliki beberapa metode penunjang keputusan yaitu AHP dan TOPSIS.

AHP pertama kali diperkenalkan oleh Thomas L Saaty adalah sebuah model penunjang keputusan. Metode ini dapat membantu memecahkan masalah dengan banyak kriteria atau faktor kompleks. Suatu permasalahan jika diuraikan menjadi beberapa kelompok kemudian disusun secara hierarki maka akan lebih terstruktur dan sistematis, dengan demikian permasalahan dapat terselesaikan dengan baik Prehanto, 2020.

Metode TOPSIS (Technique for Order Preference by Similarity to Ideal Solution) adalah sebuah metode yang digunakan untuk menyusun sistem dalam menunjang keputusan. Metode ini dapat membantu menyelesaikan masalah dengan cara mengambil alternatif yang paling baik dari jarak terdekat dengan solusi ideal positif, selain itu juga dapat memilih jarak terjauh dari solusi ideal negatif Latif, L.A, 2018.

\section{METODE PENELITIAN}

\section{Lokasi Penelitian}

Lokasi penelitian ini meliputi Kabupaten Cilacap dan Daerah Istimewa Yogyakarta dengan jarak $\pm 173 \mathrm{~km}$.

\section{Teknik Pengumpulan Data dan Sampling}

Penelitian ini menggunakan dua jenis data yaitu data primer dan data sekunder. Data primer yang didapat dari pengisian kuesioner oleh responden. Teknik yang digunakan adalah purposive sampling. Selanjutnya juga akan digunakan wawancara mendalam (in depth interview) kepada pengambil kebijakan untuk dapat diambil saran-saran untuk meningkatkan penggunaan alternatif moda transportasi dari Cilacap menuju Yogyakarta.

\section{Variabel Penelitian}

Menurut Sugiyono, 2017 variabel penelitian merupakan segala sesuatu yang berbentuk apa saja yang ditetapkan oleh peneliti untuk dipelajari sehingga diperoleh informasi tentang hal tersebut kemudian ditarik kesimpulannya. Variabel ini akan dibagi menjadi dua level yaitu level I ( kreiteria ) meliputi biaya, waktu perjalanan, keselamatan, kenyamanan, dan frekuensi. Sedangkan level II (alternatif moda transportasi) meliputi kereta api, bus dan mobil.

\section{Tahap Analisis Metode AHP}

Menurut Sham Sidhiq, 2020,gambaran analisis dengan metode AHP sebagai berikut.

a) Peneliti membuat kerangka berpikir ( goal, kriteria dan alternatif),

b) Menentukan skala prioritas dengan metode pairwise,

c) Membuat matriks berpasangan (variabel $i$ dan $j$ ),

d) Menjumlahkan tiap kolom matriks variabel menjadi matriks A,

e) Menormalisasikan matriks A menjadi matriks B,

f) Menentukan nilai setiap kriteria pada matriks B dengan menjumlahkan tiap baris,

g) Membandingkan CI dan RI sehingga diperoleh CR. Apabila CR $\leq 0,1$ maka penilaian dianggap benar.

\section{Tahap Analisis Metode TOPSIS}

Dalam melakukan analisis TOPSIS dimana hasil identifikasi alternatif moda transportasi berdasarkan tingkat kepentingan yang selanjutnya di gabung dengan penilaian pembobotan dari metode AHP. Penilaian identifikasi alternatif moda didasarkan pada pengelompokan penilaian kriteria untuk memudahkan dalam proses penilaian. Gambaran analisis dengan metode TOPSIS sebagai berikut :

a) Membuat matriks keputusan yang memuat penilaian kriteria pada masing-masing moda transportasi

b) Disusun matriks keputusan ternormalisasi

c) Menyusun matriks keputusan ternormalisasi terbobot dari hasil pembobotan metode AHP

d) Menghitung solusi ideal positif dan negatif

e) Menghitung nilai kedekatan relatif terhadap solusi ideal

f) Menghitung nilai preferensi untuk mendapatkan peringkat alternatif moda transportasi 
g) Analisis sensitivitas.

h) Hasil analisis TOPSIS merupakan peringkat dari alternatif moda transportasi.

\section{Bagan Alir Penelitian}

Tujuan utama dalam penelitian ini adalah menentukan preferensi moda transportasi antar kota antar provinsi menggunakan metode analisis AHP-TOPSIS. Dimana pertama kali data dikumpulkan dari berbagai sumber referensi, kemudian menentukan kriteria penentu dan alternatif moda transportasi dalam penelitian. Data hasil penelitian kemudian didapat dengan cara membagi kuesioner dan pengamatan langsung di lapangan. Kemudian dari hasil penelitian tersebut akan disusun saran-saran yang dapat digunakan agar ada peningkatan penggunaan moda kereta api, bis dan mobil. Analisis data penelitian akan menggunakan metode AHP-TOPSIS. Bagan alur penelitian dapat dilihat pada Gambar 1 sebagai berikut :

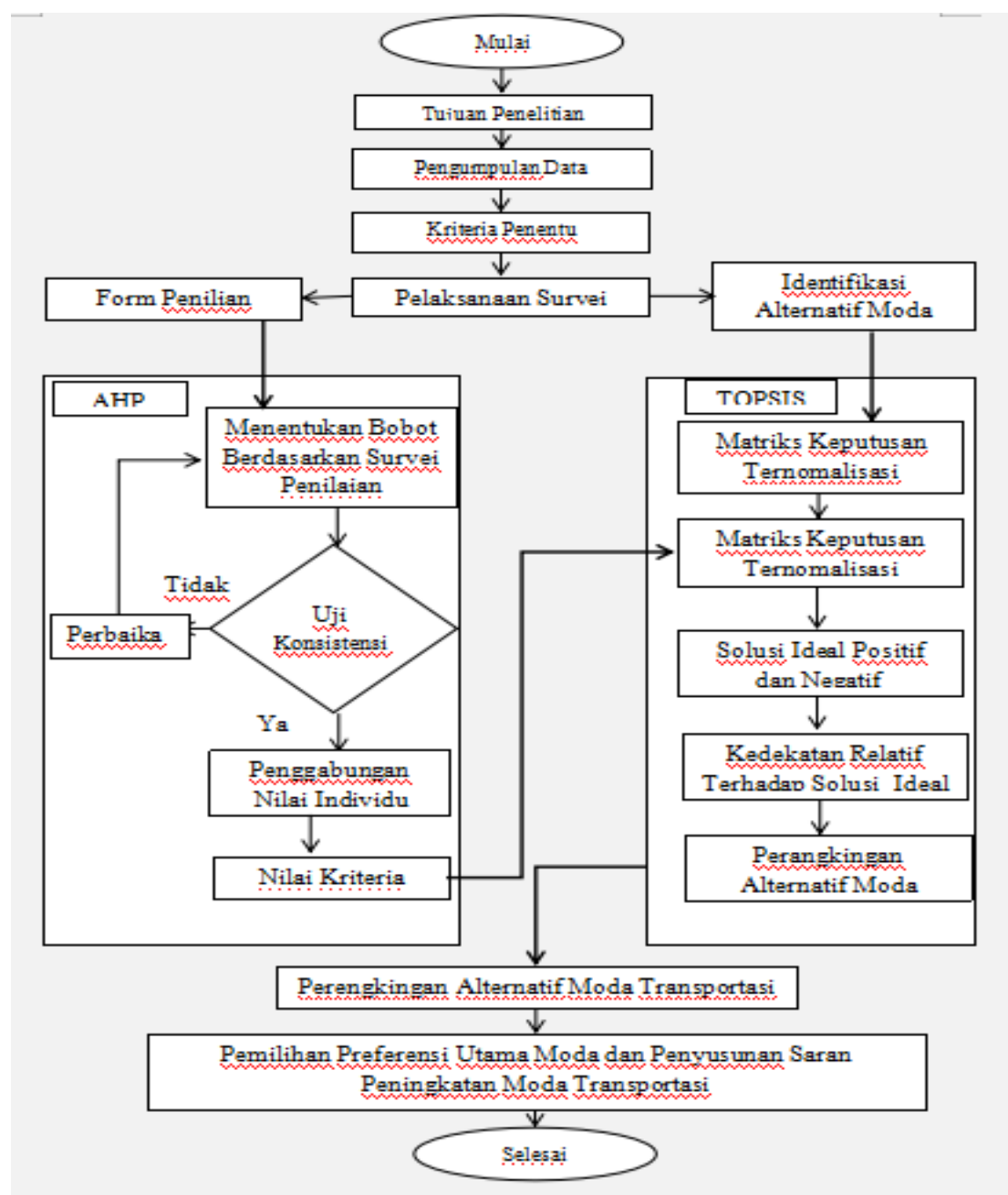

Gambar 1. Bagan alur

\section{HASIL DAN PEMBAHASAN}

Analisis Pengguna Moda Transportasi (User)

Responden pada penelitian preferensi pemilihan moda transportasi ini adalah pengguna moda transportasi (user). Dimana user adalah masyarakat umum dengan latar belakang yang berbeda. Terdapat 20 responden dalam penelitian ini. Menurut Nasution (1996), didalam memilih jenis jasa transportasi yang akan digunakan oleh penguna / pemakai moda transportasi (user) ditentukan oleh enam faktor yaitu; sifat muatan, biaya transpor, tarif transpor, pendapatan pemakai jasa angkutan (users), kecepatan angkutan, kualitas pelayanan. Dari keenam faktor tersebut jika pendapatan masyarakat meningkat maka makin meningkat permintaan akan jasa transportasi. Hal tersebut dikarenakan kebutuhan dalam melakukan perjalanan semakin meningkat. Pendapatan masyarakat dalam penelitian ini dibagi menjadi 3 kelompok yaitu: kelompok pendapatan rendah, kelompok pendapatan menengah dan kelompok pendapatan tinggi. Hasil penelitian menunjukan dari responden yang berjumlah 20 orang terdapat $55 \%$ memiliki pendapatan rendah, $10 \%$ memiliki pendapatan menengah, dan $35 \%$ memiliki pendapatan tinggi. 


\section{Analisis AHP-TOPSIS}

Penelitian menggunakan dua metode dalam menganalisis hasil penelitian yaitu AHP dan TOPSIS. Dimana nilai kriteria pemilihan moda transportasi dianalisis dengan menggunakan metode AHP dan menganalisis tiap-tiap nilai kriteria sebagai penentu pemilihan alternatif moda transportasi menggunakan metode TOPSIS.

\section{Analisis AHP}

Proses perhitungan data yang berasal dari data respon pengguna moda transportasi (user) akan diolah dengan metode AHP dibantu dengan menggunakan Microsoft Excel. Pada tabel 1 kita dapat melihat salah satu sampel data responden pengguna (user) yang telah diisi, kemudian dari data tersebut diubah menjadi matriks perbandingan berpasangan pada tabel 2, mencari rata rata geometri dari 20 responden pengguna moda transportasi (user) pada tabel 3. Tabel rata-rata geometri kelompok user kemudian di normalisasikan dan dihitung bobotnya pada tabel 4. Dari hasil analisis kemudian dilakukan uji konsistensi, kemudian didapat hasil $\mathrm{CR}=0,073$ yang dapat dilihat pada tabel 5 . Dimana nilai rasio konsistensi (CR) sebagai batas ketidakkonsistenan. Jika nilai CR $\leq 0,1$ maka disebut konsisten, sehingga data dianggap benar. Hasil dari penilaian bobot kriteria karena nilai $\mathrm{CR} \leq 0,1$ dapat digunakan sebagai masukan pada analisis ke tahap selanjutnya. Grafik hasil pembobotan AHP kelompok user dapat dilihat pada Gambar 2.

Tabel 1. Sampel perbandingan kriteria user 1

\begin{tabular}{ccllcc}
\hline No. & $(1)$ & Perbandingan Kriteria & & Skala \\
\hline $\mathrm{i}$ & $\mathrm{j}$ & $\mathrm{A}$ & B & A atau B & $1-9$ \\
1 & 2 & & Waktu Perjalanan & B & 5 \\
1 & 3 & \multirow{2}{*}{ Biaya } & Keselamatan & $\mathrm{B}$ & 7 \\
1 & 4 & & Kenyamanan & $\mathrm{B}$ & 7 \\
1 & 5 & & Frekuensi & $\mathrm{B}$ & 5 \\
2 & 3 & & Keselamatan & $\mathrm{B}$ & 7 \\
2 & 4 & Waktu Perjalanan & Kenyamanan & $\mathrm{B}$ & 7 \\
2 & 5 & & Frekuensi & $\mathrm{B}$ & 5 \\
3 & 4 & \multirow{2}{*}{ Keselamatan } & Kenyamanan & $\mathrm{A}$ & 7 \\
3 & 5 & \multirow{2}{*}{ Kenyamanan } & Frekuensi & $\mathrm{A}$ & 7 \\
4 & 5 & Frekuensi & $\mathrm{A}$ & 5 \\
\hline
\end{tabular}

Tabel 2. Sampel perhitungan matriks berpasangan user 1

\begin{tabular}{cccccc}
\hline Kriteria & Biaya & Waktu Perjalanan & Keselamatan & Kenyamanan & Frekuensi \\
\hline Biaya & 1 & 0.200 & 0.143 & 0.143 & 0.200 \\
Waktu Perjalanan & 5 & 1 & 0.143 & 0.143 & 0.200 \\
\hline \multicolumn{7}{r}{} & & & & & \\
\hline Keselamatan & 7 & 7 & 1 & 7 & 7 \\
Kenyamanan & 7 & 7 & 0.143 & 1 & 5 \\
Frekuensi & 5 & 5 & 0.143 & 0.200 & 1 \\
\hline
\end{tabular}

Tabel 3. Hasil perhitungan matriks berpasangan rata-rata kelompok user

\begin{tabular}{cccccc}
\hline Kriteria & Biaya & Waktu Perjalanan & Keselamatan & Kenyamanan & Frekuensi \\
\hline Biaya & 1 & 0.425 & 0.258 & 0.553 & 0.406 \\
Waktu Perjalanan & 2.353 & 1 & 0.269 & 0.495 & 0.889 \\
Keselamatan & 3.882 & 3.711 & 1 & 4.333 & 4.549 \\
Kenyamanan & 1.810 & 2.022 & 0.231 & 1 & 3.244 \\
Frekuensi & 2.461 & 1.125 & 0.220 & 0.308 & 1 \\
Jumlah & 11.506 & 8.283 & 1.978 & 6.689 & 10.088 \\
\hline
\end{tabular}

Tabel 4. Hasil perhitungan matriks normalisasi dan bobot kelompok user

\begin{tabular}{|c|c|c|c|c|c|c|c|}
\hline Kriteria & Biaya & $\begin{array}{c}\text { Waktu } \\
\text { Perjalanan }\end{array}$ & $\begin{array}{c}\text { Kesela } \\
\text { matan }\end{array}$ & $\begin{array}{c}\text { Kenyaman } \\
\text { an }\end{array}$ & $\begin{array}{c}\text { Frekuen } \\
\text { si }\end{array}$ & sum & bobot \\
\hline Biaya & 0.087 & 0.051 & 0.130 & 0.083 & 0.040 & 0.391 & 0.078 \\
\hline Waktu Perjalanan & 0.204 & 0.121 & 0.136 & 0.074 & 0.088 & 0.623 & 0.125 \\
\hline Keselamatan & 0.337 & 0.448 & 0.506 & 0.648 & 0.451 & 2.390 & 0.478 \\
\hline Kenyamanan & 0.157 & 0.244 & 0.117 & 0.150 & 0.322 & 0.989 & 0.198 \\
\hline Frekuensi & 0.214 & 0.136 & 0.111 & 0.046 & 0.099 & 0.606 & 0.121 \\
\hline
\end{tabular}


Tabel 5. Perhitungan uji konsistensi data gabungan kelompok user

\begin{tabular}{crcccc}
\multicolumn{1}{c}{$\mathrm{D}$} & $\mathrm{Ei}$ & $\lambda \mathrm{Max}$ & $\mathrm{CI}$ & $\mathrm{RI}$ & $\mathrm{CR}$ \\
\hline 0.413 & 5.276 & & & & \\
0.643 & 5.158 & & & & \\
2.653 & 5.551 & & & & \\
1.095 & 5.536 & & & & \\
0.620 & 5.116 & 5.328 & 0.082 & 1.120 & 0.073 \\
Sum & 27 & & & & \\
\hline
\end{tabular}

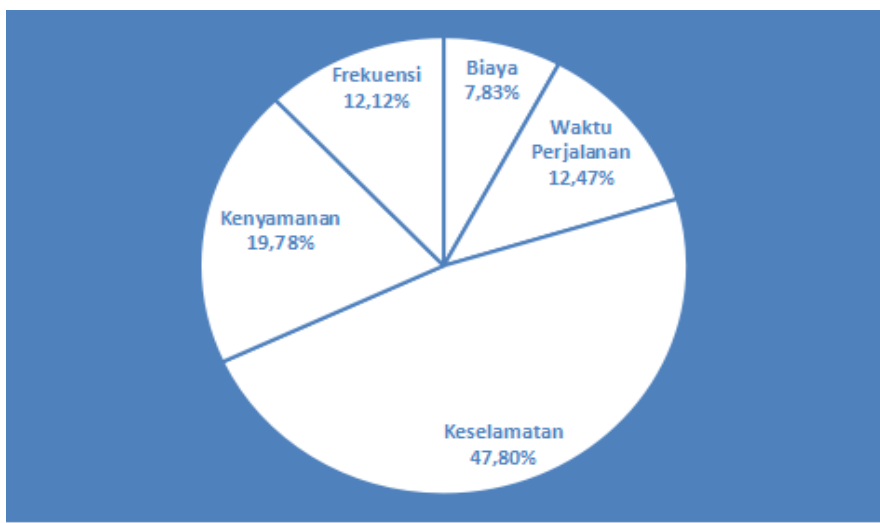

Gambar 2. Grafik bobot kriteria kelompok user

Nilai rasio konsistensi (CR) pada kelompok user sebesar 0,073 dalam hal ini masih dalam batas konsistensi yaitu $\mathrm{CR} \leq 0,1$. Seluruh responden berjumlah 20 dari kelompok user.

\section{Analisis TOPSIS}

Hasil dari analiais metode TOPSIS berupa peringkat dari alternatif moda transportasi yaitu kereta api, bus dan mobil. Tahap pertama yaitu dengan memberikan penilaian dari hasil identifikasi dengan mengacu pada klasifikasi kriteria yang telah ditentukan. Hasil penilaian di susun pada Tabel 6 berikut.

Tabel 6. Penilaian kriteria alternatif moda trasportasi

\begin{tabular}{cccccc}
\hline Moda transportasi & Biaya & Waktu perjalanan & Keselamatan & Kenyamanan & Frekuensi \\
\hline Kereta api & 3 & 5 & 5 & 5 & 3 \\
Bus & 4 & 3 & 4 & 4 & 4 \\
Mobil & 4 & 3 & 4 & 4 & 5 \\
Pembagi & 6.4031 & 6.5574 & 7.5498 & 7.5498 & 7.0711 \\
\hline
\end{tabular}

Selanjutnya tahap kedua menyusun nilai kriteria dan bobot yang telah ditentukan. Tabel 7 merupakan pembagian nilai kriteria dan bobot yang akan digunakan dalam analisis metode TOPSIS.

Tabel 7. Nilai kriteria dan bobot kriteria

\begin{tabular}{ccccc}
\hline No & Kriteria & Nilai kriteria & Bobot kriteria & Presentase (\%) \\
\hline 1 & Biaya & Cost & 0.078 & $7,9 \%$ \\
2 & Waktu perjalanan & Cost & 0.125 & $12,5 \%$ \\
3 & Keselamatan & Benefit & 0.478 & $47,8 \%$ \\
4 & Kenyamanan & Benefit & 0.198 & $19,8 \%$ \\
5 & Frekuensi & Benefit & 0.121 & $12,1 \%$ \\
\hline
\end{tabular}

Langkah-langkah analisis data dengan metode TOPSIS yaitu pertama menghitung matriks ternomalisasi pada Tabel 8, kedua menentukan keputusan terbobot pada tabel 9, ketiga menghitung matriks solusi ideal positif dan negatif pada tabel 10, keempat menghitung jarak nilai alternatif solusi ideal positif dan negatif pada tabel 11 dan terakhir menentukan nilai preferensi dapat dilihat dengan grafik pada Gambar 4. 
Tabel 8. Matriks ternomalisasi

\begin{tabular}{cccccc}
\hline Moda transportasi & Biaya & Waktu perjalanan & Keselamatan & Kenyamanan & Frekuensi \\
\hline Kereta api & 0.46852 & 0.76249 & 0.66227 & 0.66227 & 0.42426 \\
Bus & 0.62470 & 0.45750 & 0.52981 & 0.52981 & 0.56569 \\
Mobil & 0.62470 & 0.45750 & 0.52981 & 0.52981 & 0.70711 \\
\hline
\end{tabular}

Tabel 9. Matriks keputusan terbobot

\begin{tabular}{cccccc}
\hline Moda transportasi & Biaya & Waktu perjalanan & Keselamatan & Kenyamanan & Frekuensi \\
\hline Kereta api & 0.03654 & 0.09531 & 0.31656 & 0.13113 & 0.05134 \\
Bus & 0.04873 & 0.05719 & 0.25325 & 0.10490 & 0.06845 \\
Mobil & 0.04873 & 0.05719 & 0.25325 & 0.10490 & 0.08556 \\
\hline
\end{tabular}

Tabel 10 Matrik penilaian terbobot

\begin{tabular}{cccccc}
\hline Moda transportasi & Biaya & Waktu perjalanan & Keselamatan & Kenyamanan & Frekuensi \\
\hline Keterangan & Cost & Cost & Benefit & Benefit & Benefit \\
Max $\left(\mathrm{A}^{+}\right)$ & 0.03654 & 0.05719 & 0.31656 & 0.13113 & 0.08556 \\
Min $\left(\mathrm{A}^{-}\right)$ & 0.04873 & 0.09531 & 0.25325 & 0.10490 & 0.05134 \\
\hline
\end{tabular}

Tabel 11 Jarak nilai alternatif solusi ideal positif dan negatif

\begin{tabular}{cccc}
\hline Moda transportasi & $\mathbf{D}^{+}$ & $\mathbf{D}^{-}$ & ci \\
\hline Kereta api & 0.05123 & 0.06960 & 0.57602 \\
Bus & 0.07168 & 0.13626 & 0.65529 \\
Mobil & 0.06960 & 0.18888 & 0.73073 \\
\hline
\end{tabular}

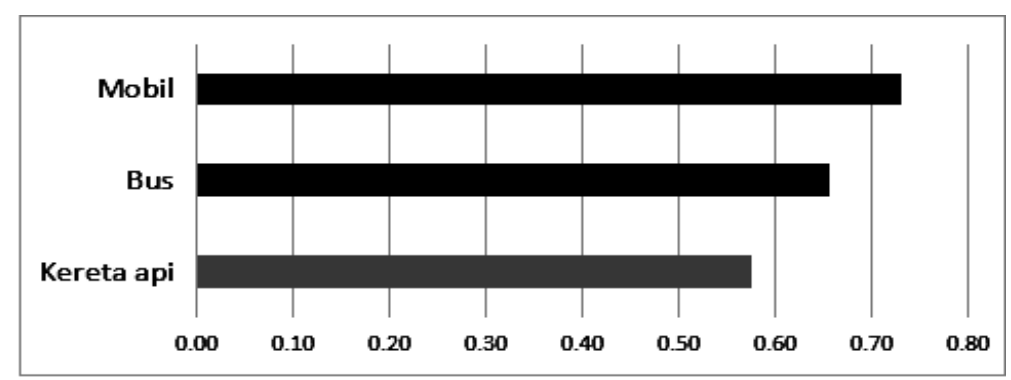

Gambar 3. Grafik preferensi analisis TOPSIS

Berdasarkan pada Gambar 3 dapat diketahui perengkingan alternatif preferensi moda transportasi dari Cilacap menuju Yogyakarta. Pada peringkat pertama moda transportasi adalah mobil, yang kedua adalah bus dan yang terakhir adalah kereta api.

\section{Analisis Sensitivitas}

Dalam memeriksa konsistensi dan ketahanan dari suatu pilihan dapat digunakan sebuah pendekatan analisis sensitivitas. Menurut Choudhary dan Shankar, 2012; Pembuaian, 2019 variasi nilai bobot dilakukan dengan cara memodelkan nilai bobot dengan nilai yang berbeda. Dalam penelitian ini akan dilakukan 6 (lima) model yaitu K1, K2, K3, K4, K5 dan K6. Jika K1 adalah kondisi awal yang memiliki nilai bobot kriteria pada AHP. Kemudian K2, K3,K4, dan K5 merupakan kondisi dimana terjadi pertukaran nilai bobot diantara dua kriteria pada AHP. Sedangkan kondisi K6 merupakan kondisi dimana nilai bobot akan sama besar yaitu membagi nilai satu dengan jumlah kriteria dan menghasilkan nilai 0,2 pada tiap tiap kriteria. Metode TOPSIS akan menganalisis hasil dari variasi bobot kriteria yang kemudian didapatkan peringkat alternatif moda transportasi. Tabel 12 berikut ini menunjukan variasi kondisi bobot kriteria analisis peringkat sensitifitas. 
Tabel 12 Variasi kondisi bobot kriteria

\begin{tabular}{ccccccccc}
\hline \multirow{2}{*}{ Kondisi } & \multicolumn{3}{c}{ Kriteria } & \multicolumn{3}{c}{ Peringkat analisis sensitivitas } \\
& 1 & 2 & 3 & 4 & 5 & Mobil & Bus & Kereta Api \\
\hline K1 & 0.078 & 0.125 & 0.478 & 0.198 & 0.121 & 1 & 2 & 3 \\
K2 & 0.125 & 0.078 & 0.478 & 0.198 & 0.121 & 1 & 2 & 3 \\
K3 & 0.478 & 0.125 & 0.078 & 0.198 & 0.121 & 1 & 2 & 3 \\
K4 & 0.198 & 0.125 & 0.478 & 0.078 & 0.121 & 1 & 2 & 3 \\
K5 & 0.121 & 0.125 & 0.478 & 0.198 & 0.078 & 1 & 3 & 2 \\
K6 & 0,2 & 0,2 & 0,2 & 0,2 & 0,2 & 1 & 2 & 3 \\
\hline
\end{tabular}

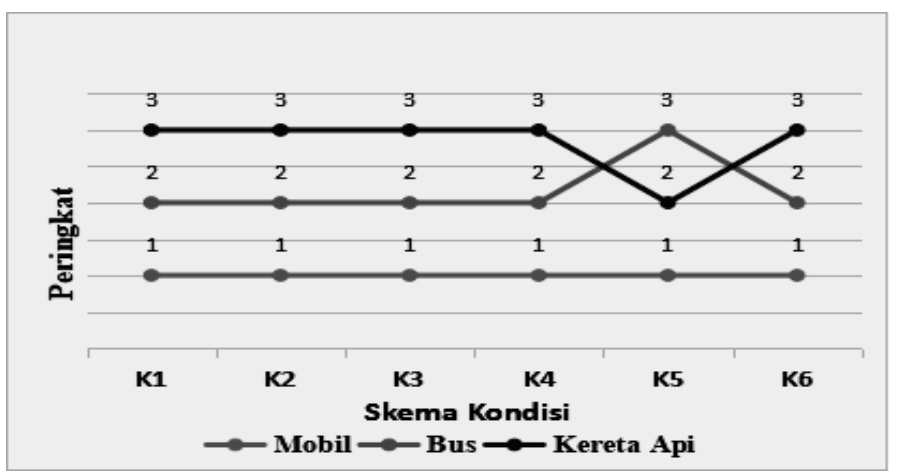

Gambar 4 Grafik peringkat analisis sensitivitas

Pada Tabel 12 menunjukan hasil dari analisis sensitifitas yang mengalami persebaran perubahan peringkat sebagai akibat dari variasi pembobotan kriteria. Persebaran peringkat sebagai akibat dari variasi pembobotan kriteria dapat dijelaskan berikut ini.

a. Peringkat I diperoleh oleh moda trasportasi mobil sebanyak 6 kali.

b. Peringkat II diperoleh oleh moda trasportasi bus sebanyak 5 kali dan kereta api sebanyak 1 kali.

c. Peringkat III diperoleh oleh moda trasportasi kereta api sebanyak 5 kali dan bus sebanyak 1 kali.

Dari hasil Gambar 4 menunjukan bahwa peringkat 1 masih diduduki oleh mobil, yang terjadi perubahan adalah peringkat ke II dan ke III pada skema kondisi ke 5 (K5) dimana kereta api berada pada peringkat II dan bus ada di peringkat III. Selebihnya bus masih berada pada peringkat ke II sebanyak 5 kali dan kereta api masih berada pada peringkat ke III sebanyak 5 kali. Karena jumlah sebaran peringkat alternatif moda transportasi masih mengarah pada kondisi awal sehingga hasil analisis sensitifitas dianggap robust atau baik. Hasil uji sensitifitas menunjukan bahwa peningkatan bobot kriteria kenyamanan akan menurunkan prioritas moda bus. Sedangkan untuk moda kereta api dapat ditingkatkan dengan cara menambahkan bobot pada kriteria biaya.

\section{Rencana Tindak Lanjut}

Proses rencana tindak lanjut hasil penelitian ini di perkuat dengan usulan perbaikan untuk masing masing moda. Usulan perbaikan didapat dengan mewawancarai narasumber. Terdapat lima narasumber yang dimintai pendapat dan idenya yaitu ahli transportasi, binamarga, dinas perhubungan, pengelola administrasi perkantoran terminal, dan tokoh masyarakat. Proses wawancara mendalam ( indepth interview) akan dilakukan dengan cara pertama menentukan identitas narasumber, kemudian menentukan jadwal penelitian, mengolah data hasil wawancara keudian yang terakhir menganalisisnya. Hasil analisis dari wawancara mendalam ini akan didapatkan saran saran yang dapat meningkatkan penggunaan alternatif moda transportasi dari Cilacap menuju Yogyakarta. Saran tersebut adalah pertama untuk moda kereta api lebih tepat mencari jam keberangkatan yang tepat untuk para penumpang. Untuk moda bus harus selalu siap jika dinas melakukan ramp check. Sedangkan untuk moda mobil harus memastikan biaya penggunaan yang keluar lebih sedikit dari biaya menggunakan transportasi umum.

\section{KESIMPULAN}

Berdasarkan hasil dari penelitian maka didapatkan kesimpulan sebagai berikut.

1. Metode AHP dapat menentukan kriteria moda transportasi yang sesuai dengan tujuan sasaran. Dengan hasil penilaian bobot kriteria yaitu keselamatan $(47,80 \%)$, kenyamanan $(19,78 \%)$, waktu perjalanan $(12,47 \%)$, frekuensi $(12,12 \%)$ dan terakhir biaya $(7,83 \%)$.

2. Metode TOPSIS dapat menentukan preferensi moda transportasi dengan hasil rangking pertama adalah moda transportasi mobil $(0,73)$, kedua dalah bus $(0,66)$, terakhir adalah kereta api $(0,58)$. 
3. Hasil uji sensitifitas menunjukan bahwa peningkatan bobot kriteria kenyamanan akan menurunkan prioritas moda bus. Sedangkan untuk moda kereta api dapat ditingkatkan dengan cara menambahkan bobot pada kriteria biaya. Hasil analisis ini dianggap robust atau baik karena jumlah sebaran peringkat alternatif moda transportasi masih mengarah pada kondisi awal.

4. Saran-saran untuk meningkatkan penggunaan alternatif moda transportasi dari Cilacap menuju Yogyakarta. Berdasarkan ide dan pendapat dari narasumber dapat diketahui terdapat perbaikan pada moda kereta api lebih tepat mencari jam keberangkatan yang tepat untuk para penumpang. Untuk moda bus harus selalu siap jika dinas melakukan ramp check. Sedangkan untuk moda mobil harus pastikan biaya yang keluar lebih sedikit dari biaya menggunakan transportasi umum.

\section{UCAPAN TERIMA KASIH}

Alhamdulillahirobbil 'alamiin, Terimaksih saya ucapkan yang sebesar besarnya kepada : Dosen Pembimbing saya yaitu Dr. Eng. Imam Muthohar, S.T.M.T. dan Prof. Ir. Siti Malkamah, M.Sc., Ph.D. Keluargaku tercinta yaitu kedua orang tuaku Dirsun dan Suharti, kakakku Desty Anna Eka Sari, Adiku Arif Tri Pambudi dan Luqman Agung Pamungkas, serta keponkan pertamaku Narendra Athallah

\section{DAFTAR PUSTAKA}

Awasthi, A., Omrani, H., \& Gerber, P. (2018). Investigating ideal-solution based multicriteria decision making techniques for sustainability evaluation of urban mobility projects. Transportation Research Part A: Policy and Practice, 116, 247-259.

Choudhary, D., \& Shankar, R. (2012). An STEEP-fuzzy AHP-TOPSIS framework for evaluation and selection of thermal power plant location: A case study from India. Energy, 42(1), 510-521.

Latif, L. A., Jamil, M., \& Abbas, S. H. (2018). Buku Ajar: Sistem Pendukung Keputusan Teori dan Implementasi. Deepublish.

Nasution, 1996. Manajemen Transportasi. Ghalia Indonesia, Jakarta.

Prehanto, D. R., Kom, S., \& Kom, M. (2020). Buku Ajar Model Sistem Pendukung Keputusan dengan AHP dan IPMS. Scopindo Media Pustaka.

Pembuaian, Ardilson. 2019. Penentuan Indeks Potensi Kecelakaan Infrastruktur Jalan Dengan Pendekatan Hybrid AHP TOPSIS. Yogyakarta: Universitas Gadjah Mada.

Sham Sidhiq. (2020). Analisis Optimalisasi Lokasi Stabling Kereta Di Pulau Jawa Dengan Metode Multikriteria AhpTopsis (Doctoral dissertation, Universitas Gadjah Mada).

Sugiyono. (2017). Metode Penelitian Kuantitatif, Kualitatif, dan R\&D. Bandung : Alfabeta, CV.

Tamin, Ofyar, Z. 2000. Perencanaan dan Permodelan Transportasi. Bandung, Indonesia: Penerbit ITB. 